\title{
Influence of day/night humidity and cation ratios and concentration in the nutrient solution on incidence of Didymella bryoniae in glasshouse cucumbers
}

\author{
N. A. M. van Steekelenburg ${ }^{1}$ and G. W. H. Welles ${ }^{2}$ \\ ${ }^{1}$ Research Institute for Plant Protection (IPO), Wageningen, seconded to the \\ Glasshouse Crops Research Station, P.O. Box 8, NL 2670 AA Naaldwijk, Nether- \\ lands \\ ${ }^{2}$ Glasshouse Crops Research Station, P.O. Box 8, NL 2670 AA Naaldwijk, Ne- \\ therlands
}

Received 29 December 1987; accepted 30 March 1988

Key words: glasshouse climate, mineral nutrition, calcium electrical conductivity, Didymella bryoniae, Mycosphaerella citrullina, Mycosphaerella melonis, stem and fruit rot, Cucumis sativus

\begin{abstract}
The effect of a low or a high humidity during the day combined with either a low or a high humidity during the night on the incidence of stem and fruit rot caused by $D i$ dymella bryoniae was examined for cucumber. The incidence of the disease on plants and fruits decreased with a lower 24-h average humidity in the range from 0.30 to $0.51 \mathrm{kPa}$ vapour pressure deficit $(87$ to $80 \%$ relative humidity, respectively). A high humidity during either the day or night had a similar effect on the incidence of the disease.

An increase of the electrical conductivity (EC) level of the nutrient solution from 2.5 to $5.0 \mathrm{dS} \mathrm{m}^{-1}\left(25^{\circ} \mathrm{C}\right)$ decreased the number of diseased leaf axils at a Ca concentration of $1.5 \mathrm{mmol} \mathrm{l}^{-1}$ with $41 \%$, but had no effect at a Ca concentration of 4.5 mmol $\mathrm{l}^{-1}$. An increase in Ca concentration from 1.5 to $4.5 \mathrm{mmol} \mathrm{l}^{-1}$ decreased the number of diseased leaf axils at an EC level of $2.5 \mathrm{dS} \mathrm{m}^{-1}$ with $26 \%$, but had no effect at an EC level of $5.0 \mathrm{dS} \mathrm{m}^{-1}$.

To optimize disease control a high humidity, a low EC level and a low Ca concentration of the nutrient solution should be avoided.
\end{abstract}

\section{Introduction}

The environmental factor humidity has gained importance in research on glasshouse crops since the energy crises of the nineteen-seventies. The glasshouse indus- 
try was forced to carry out energy-saving measures, such as thermal screens, double-glazing and reduced ventilation, to minimize heating costs. This resulted in a more humid environment which had its repercussions for the incidence of diseases.

In previous experiments, several aspects of the influence of the glasshouse climate on the incidence of stem and fruit rot in cucumber were studied, such as day and night temperature and minimum ventilator opening (van Steekelenburg \& van de Vooren. 1981), ventilation temperature (van Steekelenburg, 1984) and time of transition from night to day temperatures (van Steekelenburg, 1985). From these experiments it was concluded that humidity was the major factor determining the incidence of stem and fruit rot. However, high humidities in glasshouses cannot always be avoided. The aim of the experiment reported here was to study whether a high day humidity or a high night humidity is allowed without serious consequences for disease incidence.

Stem and fruit rot of cucumber is caused by Didymella bryoniae (Auersw.) Rehm (synonyms: Mycosphaerella citrullina (C.O.Sm.) Gross. and Mycosphaerella melonis (Pass.) Chiu and Walker). Symptoms and economic importance of the disease have been described earlier (Van Steekelenburg, 1982, 1985, 1986).

Although mineral nutrition may influence the severity of diseases (Huber, 1980; Krauss, 1969), it has received little attention in glasshouse vegetable crop research. The use of rockwool as a rooting medium for glasshouse crops renewed the attention for and facilitated the study of the effect of nutrition on incidence of diseases.

The effect of differences in electrical conductivity (EC) and Ca level in the root environment on the incidence of stem and fruit rot was examined in the study described here.

\section{Materials and methods}

\section{Glasshouse environment}

The experiment was carried out in eight double-glazed compartments $(15.0 \times 12.8$ $\mathrm{m}$ ) of a Venlo-type glasshouse, specially designed for research on the effect of humidity on plant growth and development. A computer system was used for environmental control. Dry and wet bulb temperatures were measured by screened and aspirated psychrometers developed by the Technical and Physical Engineering Research Service (TFDL) in Wageningen. From these data the relative humidity and vapour pressure deficit were calculated. For the day and night period the values were averaged over 10.00 to $16.00 \mathrm{~h}$ and 22.00 to $04.00 \mathrm{~h}$, respectively. The setpoints for heating were $24 / 21^{\circ} \mathrm{C}$ (day/night) until production started and subsequently $22 / 15{ }^{\circ} \mathrm{C}$. Setpoints for ventilation were $25 / 22$ and $23 / 16^{\circ} \mathrm{C}$, respectively.

Different humidities were obtained by applying minimum ventilation and minimum pipe temperature settings and by using a humidification system and a thermal screen as described by Bakker et al. (1987). The four combinations of continuously high $(\mathrm{h} / \mathrm{h})$ or low $(\mathrm{l} / \mathrm{l})$ and alternating low and high humidities $(\mathrm{l} / \mathrm{h}$ and $\mathrm{h} / \mathrm{l})$ during day and night (Table 1) were applied in duplicate. 
Table 1. Details of the day/night treatments for a continuous or alternating high (h) and low (l) humidity during day and night.

\begin{tabular}{|c|c|c|c|c|}
\hline \multirow{2}{*}{$\begin{array}{l}\text { Treatment } \\
\text { symbol }\end{array}$} & \multicolumn{2}{|l|}{ Minimum setting } & \multirow{2}{*}{$\begin{array}{l}\text { Screen } \\
\text { closed }\end{array}$} & \multirow[t]{2}{*}{ Humidification } \\
\hline & $\begin{array}{l}\text { pipe temperature } \\
\left({ }^{\circ} \mathrm{C}\right)\end{array}$ & $\begin{array}{l}\text { ventilation } \\
(\%)\end{array}$ & & \\
\hline$h / h^{1}$ & $0 / 0^{1}$ & $0 / 0^{1}$ & no/yes ${ }^{1}$ & yes/yes ${ }^{1}$ \\
\hline $\mathrm{l} / \mathrm{h}$ & $45 / 0$ & $40 / 0$ & no/yes & no/yes \\
\hline $\mathrm{h} / \mathrm{l}$ & $0 / 45$ & $0 / 40$ & no/no & yes/no \\
\hline 1/1 & $45 / 45$ & $40 / 40$ & no/no & no/no \\
\hline
\end{tabular}

Day/night.

\section{Nutrition}

Plants were irrigated with a complete nutrient solution (Sonneveld \& Welles, 1984) with the aid of a trickle irrigation system. The quantity of nutrient solution applied was relative to evaporation and excess solution was recirculated. Within each compartment EC levels of 2.5 and $5.0 \mathrm{dS} \mathrm{m}^{-1}\left(25^{\circ} \mathrm{C}\right)$ were maintained in the root environment. The EC levels were combined with Ca concentrations of 1.5 and $4.5 \mathrm{mmol}$ $1^{-1}$ at a constant $\mathrm{K} / \mathrm{Mg}$ ratio in the nutrient solution applied. A higher concentration of $\mathrm{Ca}$ was compensated for by lower amounts of $\mathrm{K}$ and $\mathrm{Mg}$ to obtain equal ionic strengths of the nutrient solutions. The anionic composition for all nutrient solutions was constant. EC values were determined twice a week and necessary adjustments were made to maintain the target values. The experiment was conducted in two replicates of eight plants each per compartment.

\section{Plants}

Cucumber (Cucumis sativus L.) plants, cv. Lucinde, were raised in rockwool blocks and planted in the fifth-leaf stage in the glasshouse compartments on rockwool slabs in plastic gutters on 14 August 1984 . Overall population density was 1.5 plant per $\mathrm{m}^{2}$. The plants were grown as vertical cordons and trained according to the 'umbrella' system. In this system, side shoots are removed weekly along the main stem. The growing tip of the main stem is removed after reaching the suspending wire. Two side shoots are allowed to grow down from the top which are topped $1 \mathrm{~m}$ above soil level.

\section{Disease assessment}

A spontaneous infection of $D$. bryoniae occurred. The number of diseased leaf axils of the main stem was counted mid and end October. Suspect fruits were cut longitudinally at the blossom end to check for internal rot at each harvest (twice a week) during the last three weeks of October, after which the experiment was finished. 


\section{Results}

\section{Glasshouse environment}

Differences in 24-h average temperature between treatments were small, both for the whole production period (Bakker et al., 1987) and for the last four weeks of the experiment (Table 2). The different environmental treatments resulted in differences in vapour pressure deficit and as a consequence in differences in relative humidity. The $24-h$ average relative humidity was about equal in the treatments with a high humidity during either day or night (Table 2).

\section{Effect of humidity on disease}

In the beginning of October the disease occurred almost exclusively on plants in the compartments with a continuously high humidity. At the end of October the disease still scarcely occurred on plants in the treatment with a continuously low humidity. The disease incidence on plants in the treatments with either a high day humidity or a high night humidity was ten times lower than in the treatment with a continuously high humidity (Table 3 ).

Internal fruit rot at a continuously high humidity was about five times higher than at alternating high and low humidities. High day humidity or high night humidity had a similar effect on the incidence of the disease on plants and fruits (Table 3 ).

\section{Effect of nutrition on disease}

Mid-October the incidence of the disease on plants could only be analysed at continuously high humidity. The number of diseased leaf axils was highest at the lowest EC level $(P=0.02)$ (Table 4$)$. At the end of October the disease incidence on plants for all humidity treatments was still highest at the lowest EC level $(P<0.01)$. On both dates of disease assessment, Ca concentration had only an effect on the incidence of stem rot at a low EC level.

The different EC values and $\mathrm{Ca}$ amounts had no effect on the number of fruits with internal rot.

Table 2. Average glasshouse air temperatures, vapour pressure deficits and relative humidities for the last four weeks of the experiment.

\begin{tabular}{|c|c|c|c|c|c|c|c|c|c|}
\hline \multirow[t]{2}{*}{ Treatment $^{1}$} & \multicolumn{3}{|c|}{$\begin{array}{l}\text { Temperature } \\
\left({ }^{\circ} \mathrm{C}\right)\end{array}$} & \multicolumn{3}{|c|}{$\begin{array}{l}\text { Vapour pressure } \\
\text { deficit }(\mathrm{kPa})\end{array}$} & \multicolumn{3}{|c|}{$\begin{array}{l}\text { Relative humidity } \\
(\%)\end{array}$} \\
\hline & day & night & $24 \mathrm{~h}$ & day & night & $24 \mathrm{~h}$ & day & night & $24 \mathrm{~h}$ \\
\hline $\mathrm{h} / \mathrm{h}$ & 26.0 & 21.0 & 22.9 & 0.44 & 0.25 & 0.30 & 86.8 & 86.4 & 86.5 \\
\hline $1 / h$ & 25.1 & 20.9 & 22.6 & 0.61 & 0.27 & 0.38 & 81.4 & 84.7 & 83.5 \\
\hline $\mathrm{h} / \mathrm{l}$ & 26.0 & 21.0 & 22.9 & 0.43 & 0.43 & 0.43 & 87.2 & 80.7 & 83.4 \\
\hline 1/l & 25.0 & 21.2 & 22.8 & 0.63 & 0.47 & 0.51 & 80.0 & 79.7 & 79.8 \\
\hline
\end{tabular}

1 See Table 1 for explanation of symbols. 
Table 3. Influence of continuous and alternating high and low humidity during day and night on the incidence of $D$. bryoniae in glasshouse cucumbers.

\begin{tabular}{|c|c|c|c|}
\hline \multirow[t]{2}{*}{ Treatment $^{1}$} & \multicolumn{2}{|c|}{$\begin{array}{l}\text { Diseased leaf axils on the main stem } \\
\text { (number per plant) }\end{array}$} & \multirow[t]{2}{*}{$\begin{array}{l}\text { Internally infected fruits } \\
\text { (number per plant) }\end{array}$} \\
\hline & 12 October & 30 October & \\
\hline$h / h$ & $4.70 \mathrm{a}^{2}$ & $8.65 \mathrm{a}$ & $0.45 \mathrm{a}$ \\
\hline $1 / \mathrm{h}$ & $0.15 \mathrm{~b}$ & $0.86 b$ & $0.08 \mathrm{~b}$ \\
\hline $\mathrm{h} / \mathrm{l}$ & $0.08 \mathrm{~b}$ & $0.70 b$ & $0.09 \mathrm{~b}$ \\
\hline $1 / 1$ & $0.04 b$ & $0.07 \mathrm{~b}$ & $0.01 \mathrm{~b}$ \\
\hline
\end{tabular}

${ }^{i}$ See Table 1 for explanation of symbols.

${ }^{2}$ Values in one column followed by a different letter differ significantly at $P<0.05$ (LSD test).

Table 4. Influence of nutrition on the incidence of $D$. bryoniae in glasshouse cucumbers (number of diseased leaf axils per plant).

\begin{tabular}{|c|c|c|c|c|}
\hline \multirow[t]{2}{*}{$\mathrm{EC}\left(\mathrm{dS} \mathrm{m}^{-1}\right)$} & \multicolumn{2}{|c|}{$\begin{array}{l}12 \text { October (high-humidity treatment) } \\
\mathrm{Ca}\left(\mathrm{mmol} \mathrm{I}^{-1}\right)\end{array}$} & \multicolumn{2}{|c|}{$\begin{array}{l}30 \text { October (all humidity treatments) } \\
\mathrm{Ca}\left(\mathrm{mmol} \mathrm{l}^{-1}\right)\end{array}$} \\
\hline & 1.5 & 4.5 & 1.5 & 4.5 \\
\hline 2.5 & $6.4 \mathrm{a}^{1}$ & $4.6 \mathrm{~b}$ & $4.6 \mathrm{a}$ & $3.4 \mathrm{~b}$ \\
\hline 5.0 & $3.3 b$ & $4.4 b$ & $2.7 \mathrm{~b}$ & $3.0 \mathrm{~b}$ \\
\hline
\end{tabular}

1 Values on one date followed by a different letter differ significantly at $P<0.05$ (LSD test).

\section{Discussion and conclusions}

The importance of preventing humid environmental conditions to control stem and fruit rot in cucumbers has been established in earlier experiments with artificial inoculation of plants (van Steekelenburg, 1984, 1985; van Steekelenburg \& van de Vooren, 1981). Infection pressure after artificial inoculation of plants can be too high compared to commercial conditions. The results of the present experiment confirm the important role of humidity in the development of the disease also when a spontaneous infection occurs. It may be assumed that all compartments of the glasshouse had an equal infection pressure as ascospores of $D$. bryoniae will have been present in great numbers in the air outdoors during the time of the year the experiment was conducted (van Steekelenburg, 1983). The incidence of the disease increases at a higher 24-h average humidity. High day humidity or high night humidity has a similar effect on the 24-h average humidity and on the incidence of the disease on plants and fruits. Bakker et al. (1987) observed an increase in final yield at higher daytime humidity but no effect of nighttime humidity on final yield. A combination of a high daytime humidity with a low nighttime humidity seems therefore better than the reverse when both yield and disease control are taken into account. Both the increased incidence of stem and fruit rot and the increase in production at higher humidities have been noticed in an earlier experiment as well (van Steekelenburg \& van de Vooren, 1981). 
The disease is suppressed by a higher EC level. The effect of Ca concentration on the incidence of stem rot depends on the EC level in the root environment. Although $\mathrm{Ca}$ uptake was not measured in this experiment, it is likely that compared to the other combinations it is reduced in the combination of low EC level and low Ca concentration. Ca is known to suppress diseases such as Botrytis cinerea and Fusarium species (Huber, 1980; Krauss, 1969; Sonneveld \& Voogt, 1986). No effect of nutrition on fruit infection was observed. Fruit infection takes place via the stigma of the open flower (van Steekelenburg, 1986). Apparently, nutrition plays a minor role in disease susceptibility of the stigma. To control fruit rot, the incidence of the disease on vegetative plant parts has to be controlled. This has to be achieved first of all by manipulation of the glasshouse environment.

To optimize financial returns, the different effects of glasshouse and root environment on crop productivity and fruit quality as well as on the incidence of diseases have to be known. The data presented here may be used to develop a control strategy for economic optimization.

\section{Acknowledgements}

The assistance and advice of J. C. Bakker (glasshouse environmental aspects) and C. Sonneveld (nutritional aspects) are gratefully acknowledged.

\section{References}

Bakker, J. C., G. W. H. Welles \& J. A. M. van Uffelen, 1987. The effects of day and night humidity on yield and quality of glasshouse cucumbers. Journal of Horticultural Science 62: 363-370.

Huber, D. M., 1980. The role of mineral nutrition in defense. In: J. G. Horsfall \& E. B. Cowling (Eds), Plant disease. An advanced treatise. Vol. 5, How plants defend themselves, p. 381-406. Academic Press, New York.

Krauss, A., 1969. Einfluss der Ernährung der Pflanzen mit Mineralstoffen auf den Befall mit parasitären Krankheiten und Schädlingen. Zeitschrift für Pflanzenernährung und Bodenkunde 124: 129-147.

Sonneveld, C. \& W. Voogt, 1986. Supply and uptake of potassium, calcium and magnesium of spray carnations (Dianthus caryophyllus) grown in rockwool. Plant and Soil 93: 259-268.

Sonneveld, C. \& G. W. H. Welles, 1984. Growing vegetables in substrates in the Netherlands. Proceed. ings 6th International Congress on Soilless Culture (Wageningen), p. 613-632.

Steekelenburg, N. A. M. van, 1982. Factors influencing external fruit rot of cucumber caused by Didymella bryoniae. Netherlands Journal of Plant Pathology 88: 47-56.

Steekelenburg, N. A. M. van, 1983. Epidemiological aspects of Didymella bryoniae, the cause of stem and fruit rot of cucumber. Netherlands Journal of Plant Pathology 89: 75-86.

Steekelenburg, N. A. M. van, 1984. Influence of ventilation temperature and low ventilation rates on incidence of Didymella bryoniae in glasshouse cucumbers. Acta Horticulturae 156: 187-197.

Steekelenburg, N. A. M. van, 1985. Influence of time of transition from night to day temperature on incidence of Didymella bryoniae and influence of the disease on growth and yield of glasshouse cucumbers. Netherlands Journal of Plant Pathology 91: 225-233.

Steekelenburg, N. A. M. van, 1986. Factors influencing internal fruit rot of cucumber caused by Didymella bryoniae. Netherlands Journal of Plant Pathology 92: 81-91.

Steekelenburg, N. A. M. van \& J. van de Vooren, 1981. Influence of the glasshouse climate on development of diseases in a cucumber crop with reference to stem and fruit rot caused by Didymella bryoniae. Acta Horticulturae 118: 45-56. 